\title{
DISINTEGRATION OF SLUDGE BY A TWO-STAGE TREATMENT WITH HYDROGEN PEROXIDE AND SOLID-STATE FERMENTATION BY ASPERGILLUS ORYZAE CGMCC5992
}

\begin{abstract}
A novel and safe method has been reported for wastewater sludge treatment, the first step of which is $\mathrm{H}_{2} \mathrm{O}_{2}$ pretreatment at $150 \mathrm{~cm}^{3} / \mathrm{kg}$ for $80 \mathrm{~min}$. In this step, the majority of organic substrate was degraded, and the shear stress diminished significantly. In the second step, Aspergillus oryzae further decomposed the organic substrate of sludge for 8 days, and the activities of manganese peroxidase and lignin peroxidase kept increasing. By the methods, the residual chemical oxygen demand (COD) in the sludge was much lower than that in the sludge treated with high doses of $\mathrm{H}_{2} \mathrm{O}_{2}$. These results indicate that the present study provides a feasible method to safely dispose sludge from the wastewater treatment plant.
\end{abstract}

\section{INTRODUCTION}

In the process of wastewater purification, an excessive amount of waste sludge is generated in the wastewater treatment plant. To safely dispose sludge has recently become a serious issue. The currently commonly used disposal measures include incineration, landfilling and application. However, these methods have been limited by the safety issue and secondary pollution. Several new methods, such as physical- mechanical treatment using ultrasounds [1,2], chemical treatment using ozone [2], oxidation with $\mathrm{H}_{2} \mathrm{O}_{2}$ [4, 5], and treatment with acid or alkali [6], have also been explored. The two crucial drawbacks of these methods are the too high disposal cost and secondary pollution. Therefore, ever-increasing interests were concentrated on the biological treatment of sludge with or without enzyme addition [7]. To date, there are two modes of sludge

${ }^{1}$ School of Food Science and Biotechnology, Jiangsu University, Zhenjiang 212013, P.R. China, corresponding author Z.C. Zhang, e-mail: zhangtamei@163.com

${ }^{2}$ Beijing Green Technology and Natural Biotechnology Co., Ltd., Beijing 102300, P.R. China.

${ }^{3}$ Jiangsu Polytechnic College Agriculture and Forestry, Jurong 211121, P.R. China.

${ }^{4}$ Institute of Life Sciences, Jiangsu University, Zhenjiang 212013, P.R. China. 
biodecomposition, aerobic and anaerobic. However, two critical issues, the odors and bacterial colloid of sludge, hinder the development of biological treatment. The odors of sludge are comprised of a mixture of various gases mainly including hydrogen sulfide $\left(\mathrm{H}_{2} \mathrm{~S}\right)$, mercaptans, and dimethyl sulfide. The heterogeneous nature of these odorous emissions makes odor treatment a difficult task, while the bacterial colloid from anaerobic and aerobic microorganisms brings difficulty to the interchange of substance among microorganism, sludge, and air during the process of solid state fermentation (SSF).

SSF can be simply defined as a process whereby insoluble substrates in the composts, with sufficient moisture but no or nearly no free water, are degraded by various microorganisms. Because of its higher volumetric productivity, simplicity, lower energy requirement, and lack of wastewater producing, SSF has been extensively applied in the biotreatment of solid waste or agricultural waste $[8,9]$. However, to date, few studies reported the application of SSF in the biotreatment of sludge.

A. oryzae, a deuteromycotina fungus that secretes many kinds of enzymes including protease, amylase, cellulase, and phytase, is generally recognized as safe by the Food and Drug Administration (FDA) and Association of American Feed Control Officials [10], and extensively used in wastewater disposal and bioremediation in the fermentation industries of food, feed, kojic acid, and brewery. Tung et al. [11] used A. oryzae to treat the wastewater from cassava starch processing (CSP), and 90\% COD of wastewater was finally removed under optimized treatment conditions. Bhalerao and Puranik [12] studied A. oryzae ARIFCC1054 degradation of monocrotophos (MCP) and found that this strain possessed phosphatase activity and could be used to renovate MCP-contaminated soil and treat aqueous wastes. Meng et al. [13] isolated A. oryzae 112822 from tobacco leaves that availably degraded nicotine, and firstly elucidated a pathway to degrade nicotine in fungi. After the straw in exploded stover was treated with A. ory$z a e$, the contents of cellulose and hemicellulose in the exploded and fermented corn stover (EFCS) were decreased by $24.36 \%$ and $69.90 \%$, respectively compared with the untreated one and by $17.35 \%$ and $38.59 \%(P<0.05)$, respectively, compared with the exploded one $(P<0.05)$ [2]. A. oryzae has also been widely applied in removing dyes via biodegradation or heavy metal ions by biosorption [14]. Researches also showed that cetyl dimethyl ethyl ammonium bromide (CDAB) significantly modified the biomass of $A$. oryzae and enhanced its biosorption capacity to dyes in single and binary systems [14]. These results indicate that $A$. oryzae has the potential to degrade organic materials, especially organic recalcitrant compounds.

In previous study [15], A. oryzae strain has been isolated that could degrade organic substances including difficult-to-degrade chemicals and reduced the COD of vinasse. The present study reports a new method to treat sludge with $\mathrm{H}_{2} \mathrm{O}_{2}$ and A. oryzae. After treatment by the method described, the microorganisms in the sludge were killed; the bacterial colloid was removed by the chemical action of $\mathrm{H}_{2} \mathrm{O}_{2}$ during the process of $\mathrm{H}_{2} \mathrm{O}_{2}$ pretreatment; the COD was further degraded; water was evaporated, and the volume of sludge was reduced with the growth and respiration of A. oryzae during the SSF process. 


\section{EXPERIMENTAL}

Sludge. A sludge sample was collected from the secondary settling tank of a municipal wastewater treatment plant located in Jiangdu city (Jiangsu, China) after an activated sludge treatment process. The moisture of sludge was $84.5 \%$. The samples were immediately stored at $4{ }^{\circ} \mathrm{C}$ in a refrigerator, then transported to the laboratory within $24 \mathrm{~h}$, and kept in the freezer at $-20{ }^{\circ} \mathrm{C}$ in order to avoid changes in the characteristics $[5,16]$.

Isolation and identification of A. oryzae CGMCC5992. The fungus was isolated from the sludge in Yudai River of Jiangsu University (Zhenjiang, China). After sampling, the sludge was diluted 10 -fold with aseptic water, spread onto a potato dextrose agar (PDA) plate, and incubated at $32{ }^{\circ} \mathrm{C}$ for $48 \mathrm{~h}$. The representative strains of all colony types were isolated by sub-culturing under the same condition until the formation of a single colony. The isolated typical strains were inoculated onto PDA slants, incubated at $32{ }^{\circ} \mathrm{C}$ for $72 \mathrm{~h}$, and maintained in refrigerator at $4{ }^{\circ} \mathrm{C}$.

After culture growth on PDA plate at $32^{\circ} \mathrm{C}$ for 5-7 days, the strain's configuration and color were observed, and the morphological characters including hyphae, spores, sporangium, etc., were also recorded under microscope.

A total of $10^{6}$ spores from the strain slants were aseptically inoculated into a $250 \mathrm{~cm}^{3}$ Erlenmeyer flask containing $100 \mathrm{~cm}^{3}$ of potato dextrose (PD) medium and cultured at $28^{\circ} \mathrm{C}, 150 \mathrm{rpm}$ for 4 days. The mycelial sphere was transferred into a mortar and ground into powder under the addition of liquid nitrogen. The genomic DNA of the strain was then extracted with a genomic DNA extraction kit (TaKaRa, China) according to the manufacturer's instructions. The primers for amplification of 18s-RNA regions were as follows: forward, 5'-CCTGGTTGATCCTGCCAGTA-3' and reverse, 5'-GCTTGAT CCTTCTGCAGGTT- $3^{\prime}$. PCR amplifications were performed following the manual of a fungi identification PCR kit (TaKaRa, China). Briefly, the reactions were denatured at $94{ }^{\circ} \mathrm{C}$ for $5 \mathrm{~min}$, and the PCR was run for 30 cycles with $94{ }^{\circ} \mathrm{C}$ denaturation for $1 \mathrm{~min}$, 50-55 ${ }^{\circ} \mathrm{C}$ annealing for $1 \mathrm{~min}$, and $72{ }^{\circ} \mathrm{C}$ extension for $1 \mathrm{~min}$. The PCR was ended after final extension at $72{ }^{\circ} \mathrm{C}$ for $5 \mathrm{~min}$. Gel electrophoresis was used to detect the presence and size of the amplified DNA products from CGMCC5992. The bands were excised from the gel; the DNA was recovered using a gel extraction kit (TaKaRa, China), cloned into a PMD18-T vector, and transformed into $E$. coli $\mathrm{DH} 5 \alpha \mathrm{MCR}$ competent cells according to manufacturer's instructions (TaKaRa, China). Positive colonies were blue/white screened on LB agar. The plasmid DNA was extracted with a plasmid extraction kit (TaKaRa, China) and sequenced by Shanghai Bioasia Biotechnology Co., Ltd. (Shanghai, China). The sequence was analyzed using the BLAST program (http://www.ncbi. nlm.nih.gov/ BLAST/). The resultant sequence was submitted (Accession Number: KC291246-KC291247) to the GenBank database (http://www.ncbi.nlm.nih.gov).

Inoculation and degradation of sludge. A total of $10^{6}$ spores from the strain slants were inoculated aseptically into a $250 \mathrm{~cm}^{3}$ Erlenmeyer flask containing corncob, $15 \mathrm{~g}$ 
of bran, and $30 \mathrm{~cm}^{3}$ of $\mathrm{H}_{2} \mathrm{O}$ (sterilized at $121^{\circ} \mathrm{C}$ for $60 \mathrm{~min}$ ) and incubated at $28{ }^{\circ} \mathrm{C}$ for 5 days. This culture was later used as seed to treat sludge.

Two kg of sludge and $1.2 \mathrm{~kg}$ corncob were fully mixed and treated in batch with $100,200,300$ and $400 \mathrm{~cm}^{3}$ of $30 \% \mathrm{H}_{2} \mathrm{O}_{2}$. These treatments were performed for $4 \mathrm{~h}$ at ambient temperature. Then the seed culture medium were respectively inoculated into a plastic dish containing $60 \mathrm{~g}$ of $\mathrm{H}_{2} \mathrm{O}_{2}$-treated sludge at the inoculating dose of $6 \mathrm{~g}$ and mixed thoroughly. The dishes were sealed up with preservation film to maintain the humidity. The whole SSF was conducted at $32{ }^{\circ} \mathrm{C}$ for 15 days under static condition.

Extraction of enzyme. Lignin peroxidase (LiP) and manganese peroxidase (MnP) were extracted from the samples according to Bollag et al. [17] with minor modifications. The entire soil sample from a Petri dish was transferred to a $20 \mathrm{~cm}^{3}$ capped glass tube, mixed with 1:1 (w/w) sterilized distilled water, and shaken for $30 \mathrm{~min}$ at $50 \mathrm{rpm}$. The solid phase was separated by centrifugation, and the supernatant was frozen, thawed, and centrifuged to remove particles of high-molecular-weight polysaccharide slime. The supernatant was sequentially filtrated through a Whatman No. 1 filter paper, a $0.45 \mu \mathrm{m}$ membrane filter, and an Amicon YM10 membrane. The filtrate was then analyzed for enzyme activities.

Determination of COD. A total of respective $20 \mathrm{~g}$ treated and untreated sludge plus $500 \mathrm{~cm}^{3}$ of distilled water were mixed thoroughly. The mixtures were then filtered, and $10 \mathrm{~cm}^{3}$ of filtrate were placed into a $500 \mathrm{~cm}^{3}$ grinding mouth flask, containing $10 \mathrm{~cm}^{3}$ of distilled water, $10 \mathrm{~cm}^{3}$ of $0.25 \mathrm{~mol} / \mathrm{dm}^{3} \mathrm{~K}_{2} \mathrm{Cr}_{2} \mathrm{O}_{7}$ solute, and $30 \mathrm{~cm}^{3}$ of $1 \% \mathrm{H}_{2} \mathrm{SO}_{4}$ $\mathrm{Ag}_{2} \mathrm{SO}_{4}$ solute. After $2 \mathrm{~h}$ heating at $105^{\circ} \mathrm{C}$, the $\mathrm{COD}$ was determined by back titration and addition of an ammonium and ferro iron solution ( $0.1 \mathrm{M}$ Mohr's salt) at a volumetric dose to the excessive potassium dichromate. The COD was calculated from:

$$
\mathrm{COD}_{\mathrm{Cr}}=20000\left(V_{0}-V_{1}\right) C
$$

where $V_{0}$ is the consumption of ferro iron solution in blank titration, $V_{1}$ is the consumption of ferro iron solution in sample titration, and $C$ indicates the concentration of ferro-iron solution.

The removing rate of COD in the SSF was calculated from:

$$
\mu=\frac{\mathrm{COD}_{t-2}-\mathrm{COD}_{t}}{2}
$$

where $\mu$ is the removing rate of COD on day $t\left(\mathrm{mg} / \mathrm{g}\right.$ of dry substance/day), $\mathrm{COD}_{t}$ is the COD value on day $t$, and $\mathrm{COD}_{t-2}$ represents the COD value on the day $t-2$.

Rheological behavior of activated sludge. A total of $20 \mathrm{~g}$ sample and $50 \mathrm{~cm}^{3}$ distilled water were fully mixed and filtered with filter paper (Xinhua $1^{\#}$ ). The filtrate was 
then used to analyze for rheological behavior, which was determined on a Brookfield LVDV-II rotating viscometer. During the course of measuring, the temperature was kept in the range of $29-30{ }^{\circ} \mathrm{C}$, and the speed of the rotor was in the range of 5-100 rpm. Rheological model for $A$. oryzae fermentation broth was fitted according to the powerlaw model, i.e., $\tau=K r^{n}$, where $\tau$ is the shear stress, $r$ is the shear rate, $K$ is the consistency coefficient, and $n$ represents the flow behavior index. Apparent viscosity was calculated as $\eta_{a}=K r^{n-1}$. For the case of flask culture, $r_{\max }$ represented the maximum shear rate in $250 \mathrm{~cm}^{3}$ Erlenmeyer flasks, $r_{\max }=2 \pi R / 60$, where $R$ represents the rotational speed. In the trial, $R$ was $150 \mathrm{rpm}$, and thus $\eta_{a}=15.7^{n-1} \mathrm{~K}$.

Fungal biomass estimation. Fungal biomass was detected according to the methods described by Zeng et al. [18]. $1 \mathrm{~g}$ of SSF substrate was weighed and dispersed in $5 \mathrm{~cm}^{3}$ sterile distilled water. The samples were completely homogenized to separate the whole fungal biomass from lignocellulose material. The homogenized samples stood undisturbed to settle the higher molecular weight lignocellulose material, while the fungal biomass in the supernatant was collected separately by centrifugation at $8000 \mathrm{rpm}$ for $10 \mathrm{~min}$. The fungal biomass was then dried under vacuum and weighed.

LiP and MnP activity assay. LiP activity was determined spectrophotometrically according to Tien and Kirk [19]. The activity of $\mathrm{MnP}$ was measured at $240 \mathrm{~nm}$ using $\mathrm{Mn}(\mathrm{II})$ as substrate [20]. One enzymatic unit (U) was defined as the amount of enzyme needed to oxidize $1 \mu \mathrm{mol}$ of substrate per minute under the test condition.

Data analysis. All the experiments were performed at least in triplicate, and the results were presented as mean.

\section{RESULTS AND DISCUSSION}

\subsection{IDENTIFICATION OF THE STRAIN}

The color of strain CGMCC5992 cultured on PDA plate gradually became white in the center and greenish yellow in the periphery. The color on the bottom of PDA plate within $120 \mathrm{~h}$ of incubation at $30^{\circ} \mathrm{C}$ was creamy and did not change after additional incubation period for one week. When the colony was observed under a light microscope, the hyphae were septate, and the conidia were in a string shape, spherical on the swollen round-shape acrocyst in the conidiophores head. All the macroscopic characteristics of the isolates were identical with those of the standard strain of A. oryzae (Table 1), indicating that the isolates are most likely strains of $A$. oryzae. Therefore, based on these comparable characteristics, the isolates were identified as strains of A. oryzae. An approximately $610 \mathrm{bp}$ fragment of the $18 \mathrm{~S}$ rDNA gene was amplified from the strain and sequenced. The size of the PCR band was confirmed by electrophoresis (Fig. 1a). The gene sequence of the strain is shown in Fig. 1 b. 
Macroscopic characteristics of the isolates after 5 days of incubation at $30^{\circ} \mathrm{C}$ on a PDA plate

\begin{tabular}{|l|l|}
\hline Characteristic feature & \multicolumn{1}{|c|}{ Isolates } \\
\hline Colony diameter & $56 \mathrm{~mm}$ \\
\hline Colony color & white centre and greenish yellow periphery \\
\hline Colony reverse & pale yellow \\
\hline Colony texture & wet \\
\hline Conidial color & creamy \\
\hline Nature of spores & wet \\
\hline
\end{tabular}

a)

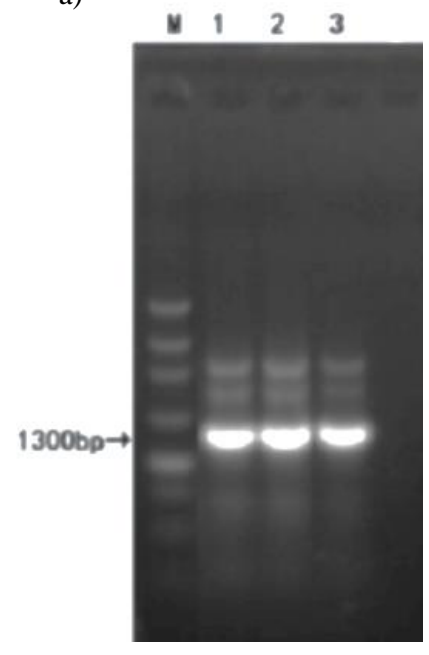

b) GGTCCGTGTTTCAAGACGGGTCGTTTACGACCATT ATGCCAGCGTCCGTGCCGAAGCGCGTTCCTCGGTC CAGGCTGGCCGCATTGCACTCCCGGCTATAAGGTG CCCCGGAGGGCACTACATTCCGGGAGCCTTTGACC GGCCGCCCAAACCGACGCTGGCCCGCCCCCAGGG AAGTACACCGGCACGAATGCCGGCTGAACCCTGG AGGCGAGTCTGGTCGCAAGCGCTTCCCTTTCAACA ATTTCACGTGCTTTTTAACTCTCTTTTCAAAGTGCT TTTCATCTTTCGATCACTCTACTTGTGCGCTATCGG TCTCCGGCCAGTATTTAGCTTTAGATGAAATTTAC CACCCATTTAGAGCTGCATTCCCAAACAACTCGAC TCGTCGAAGGAGCTTCACACGGGCGCGGACACCC CATCCCAGACGGGATTCTCACCCTCTCTGACGGCC CGTTCCAGGGCACTTAGACAGGGGCCGCACCCGA AGCATCCTCTGCAAATTACAATGCGGACCCCGAA GGAGCCAGCTTTCAAATTTGAGCTCTTGCCGCTTC ACTCGCCGTTACTGAGGCAATCCCGGTTGGTTTCT TTTCCTCCGCTTATTGATATG

Fig. 1. Result of electrophoresis of products (a) and gene sequence (b) of PCR for 18S-rDNA genes of A. oryzae CGMCC5992

The 18S rDNA sequence of strain CGMCC5992 exhibited 99\% identity with that of $A$. oryzae RIB40 (GenBank accession no. XM001818169.2), A. flavus NRRL3357 (GenBank accession no. XM002373389.1), and A. oryzae RIB40 (GenBank accession no. AP007151.1), respectively, by BLAST sequence comparison.

Based on above results of morphological characterization and sequence comparison, the isolated strain was finally identified as A. oryzae CGMCC5992.

\subsection{THE EFFECT OF $\mathrm{H}_{2} \mathrm{O}_{2}$ TREATMENT ON TEMPERATURE, COD, AND RHEOLOGICAL BEHAVIOR OF THE SLUDGE}

The temperature, $\mathrm{COD}$, and rheological behavior were analyzed at the intervals under natural $\mathrm{pH}$ during $\mathrm{H}_{2} \mathrm{O}_{2}$ treatment of the sludge. Figure $2 \mathrm{a}$ shows that the sludge 
temperature sharply increased from $17^{\circ} \mathrm{C}$ in the first 40 min after the addition of $\mathrm{H}_{2} \mathrm{O}_{2}$. However, it stopped increasing after $40 \mathrm{~min}$ of treatment. The increasing rate and range increased with the increasing amount of $\mathrm{H}_{2} \mathrm{O}_{2}$ below $300 \mathrm{~cm}^{3} / 2 \mathrm{~kg}$ of sludge. Such temperature increase is caused by addition of $\mathrm{H}_{2} \mathrm{O}_{2}$ which, releases a large amount of energy when reacting with the substance in the sludge [21].
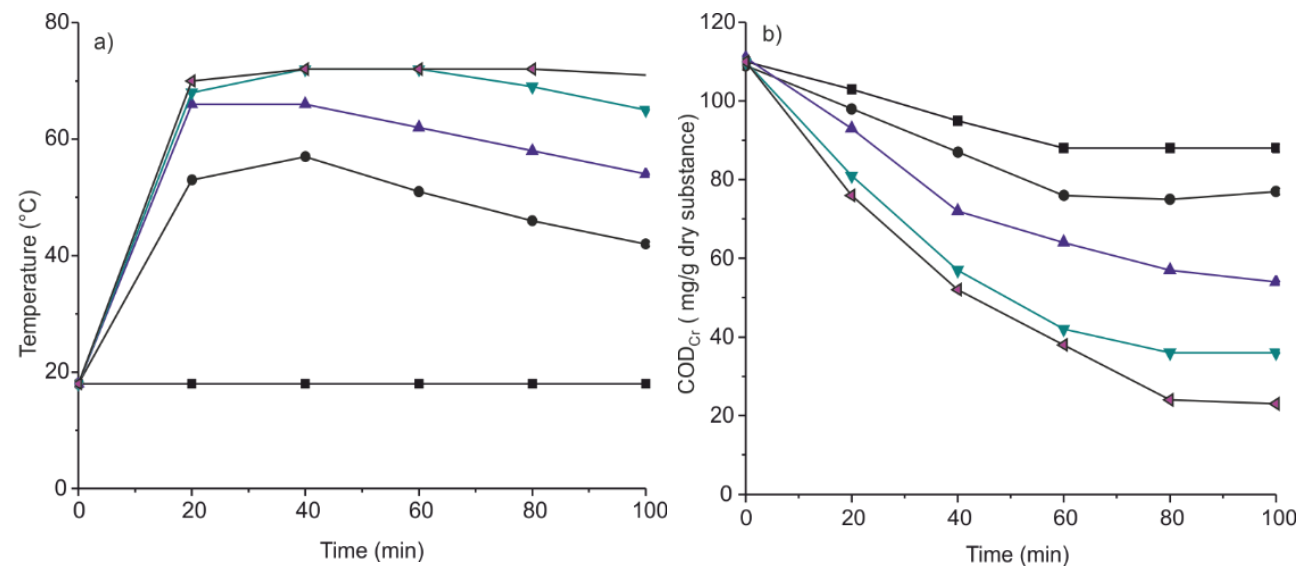

Fig. 2. Temperature (a), total COD (b) and shear stress (c) in function of the $\mathrm{H}_{2} \mathrm{O}_{2}$ processing time under various doses of $\mathrm{H}_{2} \mathrm{O}_{2}$ (in $\mathrm{cm}^{3} / 2 \mathrm{~kg}$ of sludge): $\mathbf{\square}-10,-100$, $\boldsymbol{\Delta}-200, \boldsymbol{\nabla}-300$, and $<-400$

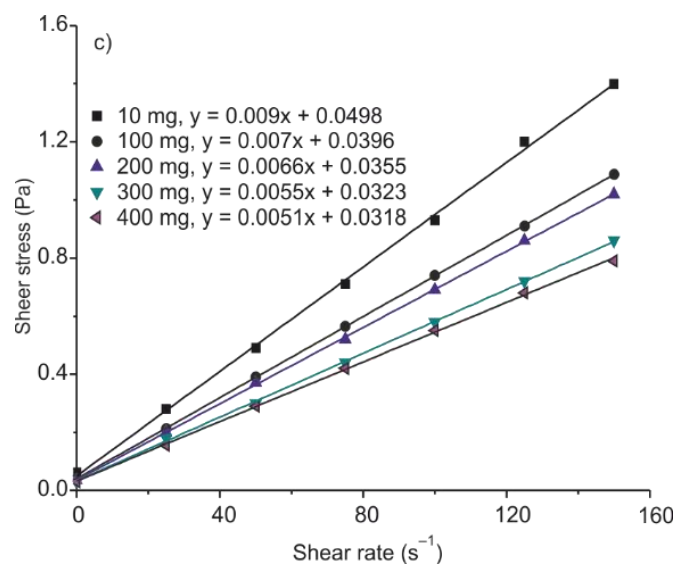

COD value in a sample was commonly used to quantify the pollution. Therefore, the COD of samples was analyzed in this study. It is clearly observed that the COD in the sludge decreased from initial $110 \mathrm{mg} / \mathrm{g}$ of sludge to $90,75,60,36$, and $22 \mathrm{mg} / \mathrm{g}$ of sludge respectively, with the increase of $\mathrm{H}_{2} \mathrm{O}_{2}$ dose from $50 \mathrm{~cm}^{3} / \mathrm{kg}$ of sludge to $200 \mathrm{~cm}^{3} / \mathrm{kg}$ of sludge in the first $80 \mathrm{~min}$ (Fig. 2b), but the COD was nearly stable thereafter. A possible explanation is the presence of mineral ions, such as $\mathrm{Fe}^{2+}, \mathrm{Cu}^{2+}, \mathrm{Mn}^{2+}$, etc., and enzymes, such as $\mathrm{MnP}$ and LiP, secreted by some bacteria and fungi. These ions and enzymes catalyzed the hydrogen peroxide to generate hydroxyl radical, which may attack the complex structure in recalcitrant substrates and degrade many other chemical compounds, including 
dyes, chlorinated aromatics, polycyclic aromatic hydrocarbons (PAHs), etc. The above analysis was also applicable to the correlation between shear stress and dose of $\mathrm{H}_{2} \mathrm{O}_{2}$.

The dependences of the shear stress $\tau$ on the shear rate $\gamma$ at various concentrations of $\mathrm{H}_{2} \mathrm{O}_{2}$ (Fig. 2c) clearly show that the filtrate from the mixture of $20 \mathrm{~g}$ of the sample and $50 \mathrm{~cm}^{3}$ of distilled water presented a non-Newtonian behavior. Therefore, the experimental data were fitted to a classical Bingham model:

$$
\tau=\tau_{B}+\eta_{B} \gamma
$$

where $\tau_{B}$ and $\eta_{B}$ are the Bingham shear stress and the Bingham viscosity, respectively.

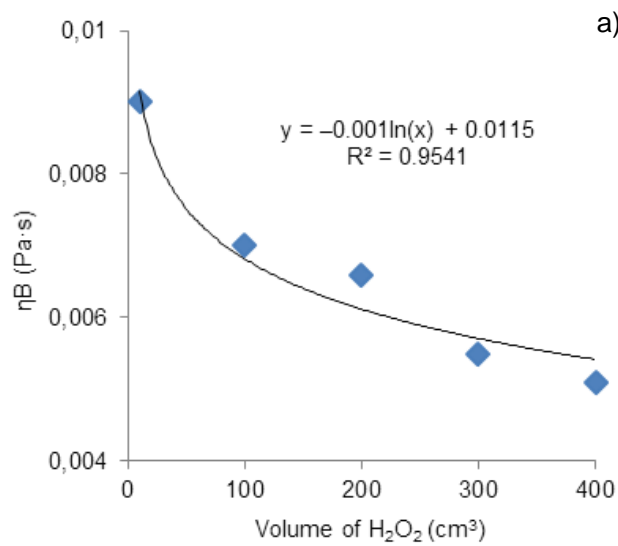

a)

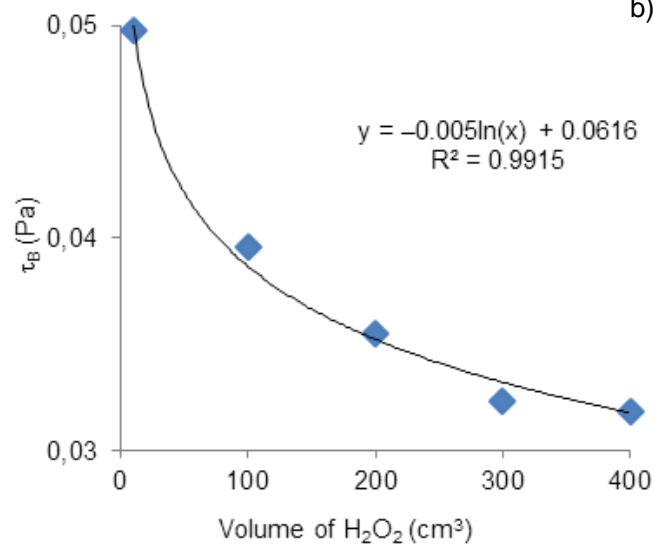

Fig. 3. Yield stress (a) and the Bingham viscosity (b) in function of the dose of $\mathrm{H}_{2} \mathrm{O}_{2}$

Figures $3 \mathrm{a}$ and $3 \mathrm{~b}$ reveal the dependence of $\tau_{B}$ and $\eta_{B}$ on the dose of $\mathrm{H}_{2} \mathrm{O}_{2}$ which both showed logarithmic decrease upon increasing the dose of $\mathrm{H}_{2} \mathrm{O}_{2}$. This might be explained by the degradation of the solubilized exopolymers, especially high viscosity organic compounds such as bacterial colloid. Hammadi et al. [22] studied the effect of $\mathrm{H}_{2} \mathrm{O}_{2}$ on liquid waste sludge and proved that $\mathrm{H}_{2} \mathrm{O}_{2}$ could reduce the content of organic matter in the final sludge. The change in apparent viscosity of the sludge further demonstrated the above conclusion that $\mathrm{H}_{2} \mathrm{O}_{2}$ could modify the sludge structure, decrease the bacterial colloid, and hence facilitate the substance exchange during the SSF of sludge.

\subsection{THE PROFILE OF BIOMASS AND COD CHANGE}

OF THE SLUDGE IN THE PROCESS OF SOLID STATE FERMENTATION

To study the impact of pretreatment with various doses of $\mathrm{H}_{2} \mathrm{O}_{2}$ on the SSF of A. oryzae, $6 \mathrm{~g}$ of seed culture medium were inoculated into a plastic dish containing $60 \mathrm{~g}$ of pretreated sludge with various doses of $\mathrm{H}_{2} \mathrm{O}_{2}$ for $80 \mathrm{~min}$. Then the samples were analyzed for biomass and COD at the intervals of $48 \mathrm{~h}$. 

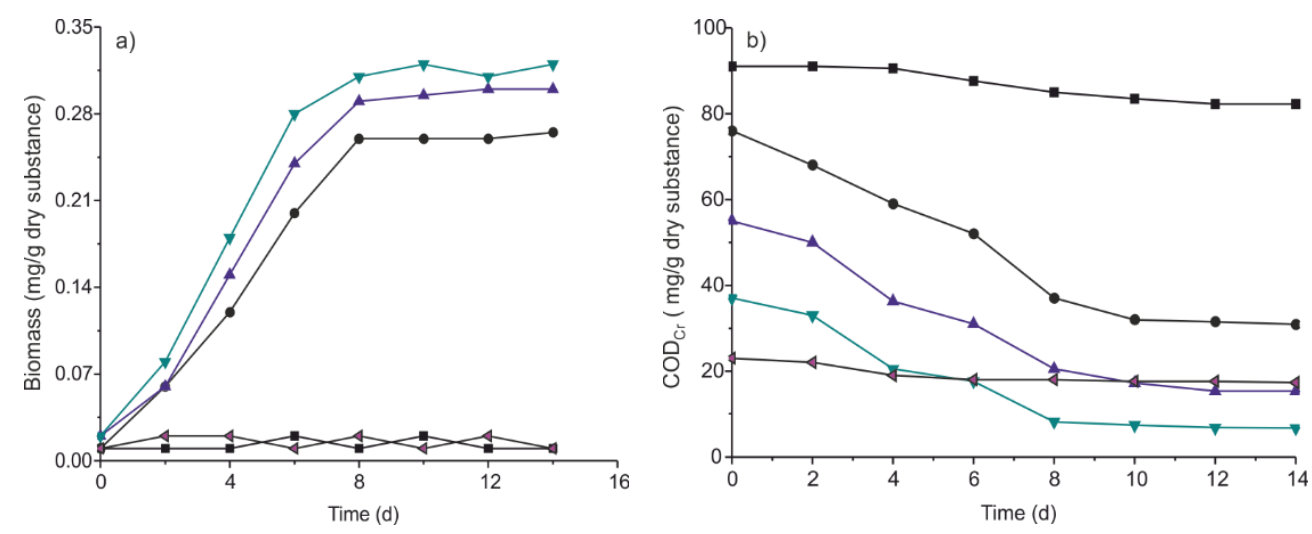

Fig. 4. Time dependences of the biomass content (a), total COD (b) and removing rate of total COD (c) of SSF with the sludge pretreated under various doses of $\mathrm{H}_{2} \mathrm{O}_{2}$ (in $\mathrm{cm}^{3} / 2 \mathrm{~kg}$ of sludge): $\mathbf{- 1 0}-100$, $\boldsymbol{\Delta}-200, \boldsymbol{\nabla}-300, \boldsymbol{4}-400$

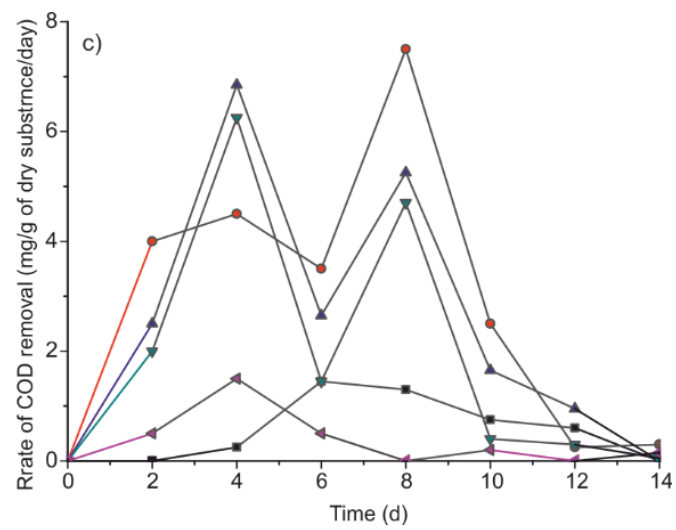

The results indicate that $A$. oryzae failed to grow in the sludge pretreated with 5 or $200 \mathrm{~cm}^{3}$ of $\mathrm{H}_{2} \mathrm{O}_{2} / \mathrm{kg}$ of sludge (Fig. 4a). Similarly, malodor was emitted from the sludge pretreated by $\mathrm{H}_{2} \mathrm{O}_{2}$ at $5 \mathrm{~cm}^{3} / \mathrm{kg}$ of sludge, while the sludge was smoother. In previous studies, malodor was reported to be composed of $\mathrm{H}_{2} \mathrm{~S}$, mercaptans, and dimethyl sulfide. It is believed that the amount of bacterial colloid removal did not meet the growth requirement of $A$. oryzae when $\mathrm{H}_{2} \mathrm{O}_{2}$ was supplied at $5 \mathrm{~cm}^{3} / \mathrm{kg}$ of sludge; therefore, the strain could not grow under such conditions. Although $\mathrm{H}_{2} \mathrm{O}_{2}$ is an oxidant, it cannot inhibit the growth of microorganism under too low concentration. When supplied at the dose of $200 \mathrm{~cm}^{3} / \mathrm{kg}$ of sludge, excessive $\mathrm{H}_{2} \mathrm{O}_{2}$ also inhibited the growth of $A$. oryzae, and the mycelia growth was not observed too. When the dose of $\mathrm{H}_{2} \mathrm{O}_{2}$ increased from $50 \mathrm{~cm}^{3} / \mathrm{kg}$ of sludge to $150 \mathrm{~cm}^{3} / \mathrm{kg}$ of sludge, the amount of bacterial colloid removed from the sludge gradually increased, the material transfer and growth of A. oryzae mycelia in the SSF were facilitated. The strain biomass in the process of SSF was found to fast increase from 2nd to 8th day (Fig. 4a). COD analysis also showed that when the dose of $\mathrm{H}_{2} \mathrm{O}_{2}$ was lower than $150 \mathrm{~cm}^{3} / \mathrm{kg}$ of sludge (Fig. 4b), the amount of COD removal was sharply increased and correlated with the dose of $\mathrm{H}_{2} \mathrm{O}_{2}$, and the COD was 
removed from 2nd to 8th day of SSF (Fig. 4c). Therefore, the optimal condition to dispose sludge with $\mathrm{H}_{2} \mathrm{O}_{2}$ and $A$. oryzae was determined as pretreating the sludge with $\mathrm{H}_{2} \mathrm{O}_{2}$ for $80 \mathrm{~min}$ at the dose of $150 \mathrm{~cm}^{3} / \mathrm{kg}$ of sludge, and further degrading the organic substance in the sludge by SSF with A. oryzae for 8 days. When the dose of $\mathrm{H}_{2} \mathrm{O}_{2}$ increased from 50 to $150 \mathrm{~cm}^{3} / \mathrm{kg}$ of sludge, the removal rate of COD exhibited 2 maxima on days 3 and 8, respectively (Fig. 4c).

\subsection{ENZYMATIC ACTIVITY IN THE SLUDGE IN THE PROCESS OF SSF}

Recalcitrant substrates were the major organic substances in the sludge which cannot be degraded by the common microorganisms. Their degradation requires special enzymes such as $\mathrm{MnP}$ and LiP, two groups of peroxidases involved in the degradation of lignin and recalcitrant compounds. Most studies indicated that LiP and MnP were simultaneously synthesized by a strain. But in this study, the synthesis of MnP and LiP was found to be with different time frame (Fig. 5).
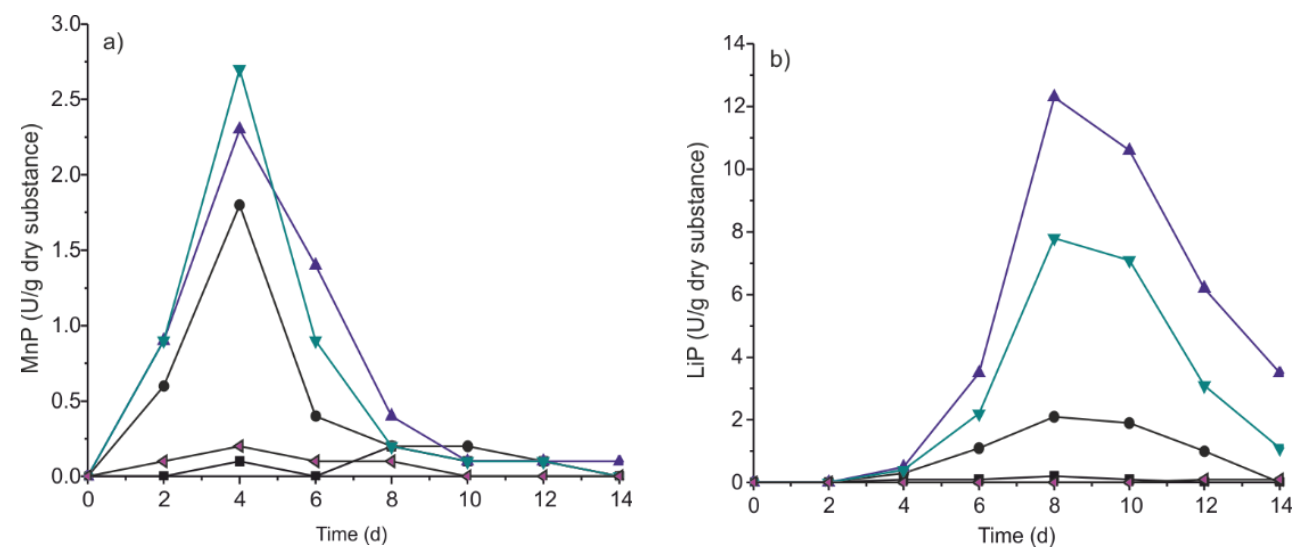

Fig. 5. Time dependences of MnP (a) and LiP (b) activities of SSF with the sludge pretreated under various doses of $\mathrm{H}_{2} \mathrm{O}_{2}$ (in $\mathrm{cm}^{3} / 2 \mathrm{~kg}$ of sludge) :

- $-10,-100, \boldsymbol{\Delta}-200, \boldsymbol{\nabla}-300$, and $-400$

The strain began to synthesize MnP from the start of SSF which reached peak value on the third day (Fig. 5a) and ceased completely before 10th day, whereas LiP was synthesized between the 4th and 10th day, reached peak value on the 8th day and ceased completely till 14th day (Fig. 5b). The timing of synthesis of the two enzymes was consistent with the two peaks of COD removal rate on days 3 and 8 during SSF, and accompanied with the fast growth of the strain. We believe that $A$. oryzae obtained certain nutrients to sustain its growth requirement by degrading substrates in the sludge with $\mathrm{MnP}$ and LiP. Primary metabolite is defined as a metabolite that is directly involved in normal growth, development, and reproduction, and usually performs physiological functions [23]. We concluded that $\mathrm{MnP}$ and LiP involved in the production of primary, 
not secondary metabolites in $A$. oryzae, though they were assumed to be parts of the secondary metabolism in many previous studies $[19,20]$. A. oryzae cannot grow in sludge without the addition of carbohydrate or other easy carbon source because carbohydrates in the sludge are easily degradable by microorganisms, while the difficult to degrade compounds in the sludge cannot be used in the absence of ligninolytic enzyme. In many previous studies, a slight amount of glucose was added into the medium which initiated the synthesis of ligninlyotic enzymes by corresponding microorganisms.

\section{CONCLUSION}

A novel strategy has been established to dispose the sludge from wastewater treatment plant. In the first stage, $\mathrm{H}_{2} \mathrm{O}_{2}$ pretreatment increased the temperature, significantly decreased the COD and apparent viscosity of the sludge, and facilitated the substance interchange during the process of SSF. In the second stage of SSF, A. oryzae grew well in the sludge pretreated by $\mathrm{H}_{2} \mathrm{O}_{2}\left(50-150 \mathrm{~cm}^{3} / \mathrm{kg}\right.$ of sludge) and further degraded the COD of substance. The removal rate of COD displayed 2 maxima on days 3 and 8 , respectively. In the process of treatment sludge, A. oryzae produced $\mathrm{LiP}$ and $\mathrm{MnP}$, which is close related with disintegration of sludge. Taking into account such advantages as no secondary pollution, and low disposal cost, the strategy is promising to eliminate organic matter in sludge.

\section{ACKNOWLEDGEMENT}

This work was supported by the grant from the Department of Sequencing, Shanghai, and grants from the National Natural Science Foundation of China (No. 31101269), Natural Science Foundation of Jiangsu Province (No. BK2011154), Nantong Social Development Fund (No. S2011003), and a project funded by the Priority Academic Program Development of Jiangsu Higher Education Institutions.

\section{REFERENCES}

[1] Braguglia C.M., Gagliano M.C., Rossetti S., High frequency ultrasound pretreatment for sludge anaerobic digestion. Effect on floc structure and microbial population, Bioresource Technol., 2012, $110(3), 43$.

[2] Chang J., Cheng W., Yin Q.Q., Zuo R.Y., Song A.D., Zheng Q.H., Wang P., Wang X., Liu J.X., Effect of steam explosion and microbial fermentation on cellulose and lignin degradation of corn stover, Bioresource Technol., 2012, 104 (3), 587.

[3] ERden G., Demir O., Filibeli A., Disintegration of biological sludge. Effect of ozone oxidation and ultrasonic treatment on aerobic digestibility, Bioresource Technol., 2010, 101 (21), 8093.

[4] Abelleira J., Perez-Elvira S.I., Sanchez-Oneto J., Portela J.R., Nebot E., Advanced thermal hydrolysis of secondary sewage sludge. A novel process combining thermal hydrolysis and hydrogen peroxide addition, Resour. Conserv. Rec., 2012, 59 (1), 52.

[5] Kim T.H., LeE S.R., NAM Y.K., YANG J., PARK C., LeE M., Disintegration of excess activated sludge by hydrogen peroxide oxidation, Desalination, 2009, 246 (1-3), 275. 
[6] KIM D.H., LEE D.Y., KiM M.S., Enhanced biohydrogen production from tofu residue by acid/base pretreatment and sewage sludge addition, Int. J. Hydrogen Energ., 2011, 36 (21), 3922.

[7] YANG Q., LuO K., Li X.M., WANG D.B., ZHENG W., Zeng G.M., LiU J.J., Enhanced efficiency of biological excess sludge hydrolysis under anaerobic digestion by additional enzymes, Bioresource Technol., 2010, 101 (9), 2924.

[8] SOLANGE I.M., JOSÉ A.T., Increase in the fructooligosaccharides yield and productivity by solid-state fermentation with Aspergillus japonicus using agro-industrial residues as support and nutrient source, Biochem. Eng. J., 2010, 53 (1), 154.

[9] IANDolo D., Amore A., Birolo L., Leo G., Olivieri G., Faraco V., Fungal solid state fermentation on agro-industrial wastes for acid wastewater decolorization in a continuous flow packed-bed bioreactor, Bioresource Technol., 2011, 102 (16), 7603.

[10] Marui J., Ohashi-Kunihiro S., Ando T., Nishimura M., Koike H., Machida M., Penicillin biosynthesis in Aspergillus oryzae and its overproduction by genetic engineering, J. Biosci. Bioeng., 2010, $110(1), 8$.

[11] Tung T.Q., MiYATA N., IwAHORI K., Growth of Aspergillus oryzae during treatment of cassava starch processing wastewater with high content of suspended solids, J. Biosci. Bioeng., 2004, 97 (5), 329.

[12] Bhalerao T.S., PURANiK P.R., Microbial degradation of monocrotophos by Aspergillus oryzae, Int. Biodeter. Biodegr., 2009, 63 (4), 503.

[13] Meng X.J., Lu L.L., Gu G.F., XIAO M., A novel pathway for nicotine degradation by Aspergillus oryzae 112822 isolated from tobacco leaves, Res. Microbiol., 2010, 161 (7), 626.

[14] YANG Y.Y., Jin D.F., WANG G., Wang S., JiA X.M., Zhao Y.H., Competitive biosorption of acid blue 25 and acid red 337 onto unmodified and CDAB-modified biomass of Aspergillus oryzae, Bioresource Technol., 2011, 102 (16), 7429.

[15] Zhang Z.C., Liu D., Feng F., Li J.S., Ming L., Pang Q.X., Chen K.P., Optimization of the nutrition for biodegradation of vinasse by Aspergillus oryzae using response surface methodology, Water Sci. Technol., 2013, 67 (4), 772.

[16] FORSTER C., The rheological and physico-chemical characteristics of sewage sludges, Enzyme Microb. Technol., 2002, 30, 340.

[17] Bollag J.M., Chen C.M., SARKAR J.M., Loll M.J., Extraction and purification of a peroxidase from soil, Soil Biol. Biochem., 1987,19 (1), 61.

[18] Zeng J.J., Singh D., Chen S.L., Biological pretreatment of wheat straw by Phanerochaete chrysosporium supplemented with inorganic salts, Bioresource Technol., 2011, 102 (3), 3206.

[19] TIEN M., KIRK T.K., Lignin-degrading enzyme from Phanerochaete chrysosporium: purification, characterization and catalytic properties of a unique $\mathrm{H}_{2} \mathrm{O}_{2}$-requiring oxygenase, Proc. Natl. Acad. Sci. USA, 1984, 81 (8), 2280.

[20] Kuwahara M., Glenn J.K., Morgan M.A., Gold M., Separation and characterization of two extracellular $\mathrm{H}_{2} \mathrm{O}_{2}$-dependant oxidases from ligninolytic culture of Phanerochaete chrysosporium, FEBS Lett., 1984, 169 (2), 247.

[21] FuKUZUMi S., YAmAda Y., KARLIN K.D., Hydrogen peroxide as a sustainable energy carrier. Electrocatalytic production of hydrogen peroxide and the fuel cell, Electrochim. Acta, 2012, 82 (1), 493.

[22] Hammadi L., Ponton A., BelhadRi M., Effects of heat treatment and hydrogen peroxide $\left(\mathrm{H}_{2} \mathrm{O}_{2}\right)$ on the physicochemical and rheological behavior of an activated sludge from a water purification plant, Proc. Eng. 2012, 33 (3), 293.

[23] Demain A.L., SANchez S., Microbial synthesis of primary metabolites, [in:] A.R. Allman (Ed.), Fermentation Microbiology and Biotechnology, 3rd Ed., The Chemical Rubber Company Press, Boca Raton, Florida, 2011, 77. 